\title{
ECOTOURISM DEVELOPMENT OF SNORKELING AND DIVING ACTIVITY TOWARD CORAL REEF HABITATS IN THE LEMUKUTAN ISLAND OF BENGKAYANG REGENCY
}

\author{
Arif Rudianto $^{1}$ - Yohana S.K. Dewi ${ }^{1}$ - Burhanuddin ${ }^{1}$
}

Ringkasan Lemukutan Island has the potential of coral reefs to be developed into snorkeling and diving destinations. This study aims to (1) Analyze the suitability and carrying capacity of Lemukutan Island Conservation area in the development of snorkeling and diving ecotourism; (2) Formulate a strategy for developing Snorkeling and diving ecotourism in Lemukutan Island. Primary data collection with field observations and structured interviews to 30 respondents on Lemukutan Island. Secondary data is collected by various libraries and related. Based on results of the study, Lemukutan Island's coral reef ecosystem for the purpose of snorkeling and diving tourism was in the appropriate category (S2) with an IKW value of $76.8 \%$ and $68.86 \%$. While the Ecological Carrying Capacity of each $\pm 6,139$ people / day and $\pm 1,008$ people / day. Based on the results of the SWOT analysis obtained alternatif strategies (1) Management and utilization of coral reefs optimally by taking into account the sustainability; (2) Increased access to Lemukutan is-

\footnotetext{
$\left.{ }^{1}\right)$ Magister Ilmu Lingkungan, Universitas Tanjungpura, Pontianak

E-mail: rudideepdiver@gmail.com
}

lands, such as speed boats and timely departures; (3) Adding snorkeling and diving equipment, and improving resort services; (4) Arrangement of land and sea space in accordance with its designation so that marine resources can be sustainable; (5) Packaging of unique and environmentally based snorkeling and diving tours; (6) Increasing promotion through digital technology and promotion through tourism events to build partnership networks; (7) Improving skills for the community to open up alternative opportunities for new jobs; (8) Disseminating the importance of protecting coral reefs and making rules for snorkeling and diving tours.

Keywords snorkeling, diving, ecotourism, coral reefs, Lemukutan Island

Received : 13 Mei 2019

Accepted : 21 Nopember 2019

\section{PENDAHULUAN}

Kekayaan sumber daya pesisir dan laut yang sangat potensial akan memberikan keuntungan apabila dimanfaatkan secara maksimal dan lestari. Berba- 
gai sektor pembangunan dapat dikembangkan dengan memanfaatkan wilayah tersebut, sehingga memberikan kontribusi dalam menggerakkan perekonomian negara. Salah satu sektor yang dapat dikembangkan adalah wisata bahari (Dahuri, 2003).

Kabupaten Bengkayang merupakan kabupaten pesisir yang terletak di Provinsi Kalimantan Barat, memiliki potensi yang cukup besar di sektor wisata bahari. Hal ini dilatarbelakangi oleh kondisi alamnya yang mempesona dan alami, beberapa gugusan pulau kecil yang kaya potensi bawah air seperti ikan, terumbu karang menjadi daya tarik tersendiri karena berbeda dengan obyek wisata di daerah lain. Salah satu wisata bahari yang potensial dikembangkan adalah wisata Snorkeling \& diving.

Peluang wisata Snorkeling dan diving pada kawasan ini merupakan salah satu solusi yang dapat dipertimbangkan dalam usaha pengembangan wisata, melalui ekowisata ini pemanfaatan ekosistem karang dapat lebih konservatif, diperhatikan dan menghasilkan keuntungan yang lainnya. Oleh karena itu perlu adanya kajian dalam pengembangan kegiatan wisata Snorkeling dan $d i$ ving pada habitat terumbu karang di $\mathrm{Pu}-$ lau Lemukutan. Penelitian ini bertujuan untuk : (1) Menganalisis kesesuaian dan daya dukung kawasan Perairan Pulau Lemukutan dalam pengembangan ekowisata snorkeling dan diving; (2) Merumuskan strategi pengembangan ekowisata Snorkeling dan diving di Pulau Lemukutan.

\section{MATERI DAN METODE}

Penelitian ini dilaksanakan di perairan Pulau Lemukutan, Kecamatan Sungai
Raya, Kabupaten Bengkayang. Waktu penelitian selama 6 bulan pada bulan Januari juni 2016 yang terbagi ke dalam tiga tahap, yaitu penelitian pendahuluan, pengumpulan data tentang kawasan kemudian pengolahan data.

Secara geografis pulau Lemukutan terletak di $0^{\circ} 42^{\prime} 6,31^{\prime \prime} \mathrm{LU}-0^{\circ} 48^{\prime} 32,91^{\prime \prime}$ LU dan $108^{\circ} 40^{\prime} 55,08^{\prime \prime}$ BT - $108^{\circ} 44^{\prime \prime}$ $25,04^{\prime \prime}$ BT (Gambar 1). Secara administratif, pada sebelah utara berbatasan dengan kota Singkawang, sebelah selatan berbatasan dengan kecamatan Sungai Raya sedangkan di sebelah timur dan barat berbatasan dengan laut Natuna.

Sumber data yang dipergunakan dalam penelitian ini adalah sumber data primer dan sekunder. Sumber data primer diperoleh dengan observasi (Nawawi and Martini, 1996) dan structured interview (Kuntjara, 2006), Sumber data sekunder diperoleh dari penelitian sebelumnya dan dari publikasi yang diterbitkan oleh beberapa instansi yang berkaitan dalam penelitian ini.

Aspek parameter lingkungan pembatas terumbu karang seperti kecerahan, tutupan karang, jenis life form, jenis ikan karang, keceparan arus, kedalaman, luas hamparan datar karang dilakukan pada tiap titik sampling tersebut dan diambil di 5 stasiun. Proses pengambilan sampel menggunakan metode purposive sampling yang didasarkan pada pertimbangan bahwa stasiun yang dipilih dapat mewakili kawasan perairan Pulau Lemukutan secara keseluruhan dengan jumlah pengambilan sampel masing-masing 3 kali pengulangan di tiap stasiun. Pengambilan sampel dilaksanakan pada bulan juni 2016. Sedangkan aspek kondisi terumbu karang dilakukan Pengukuran tutupan karang 


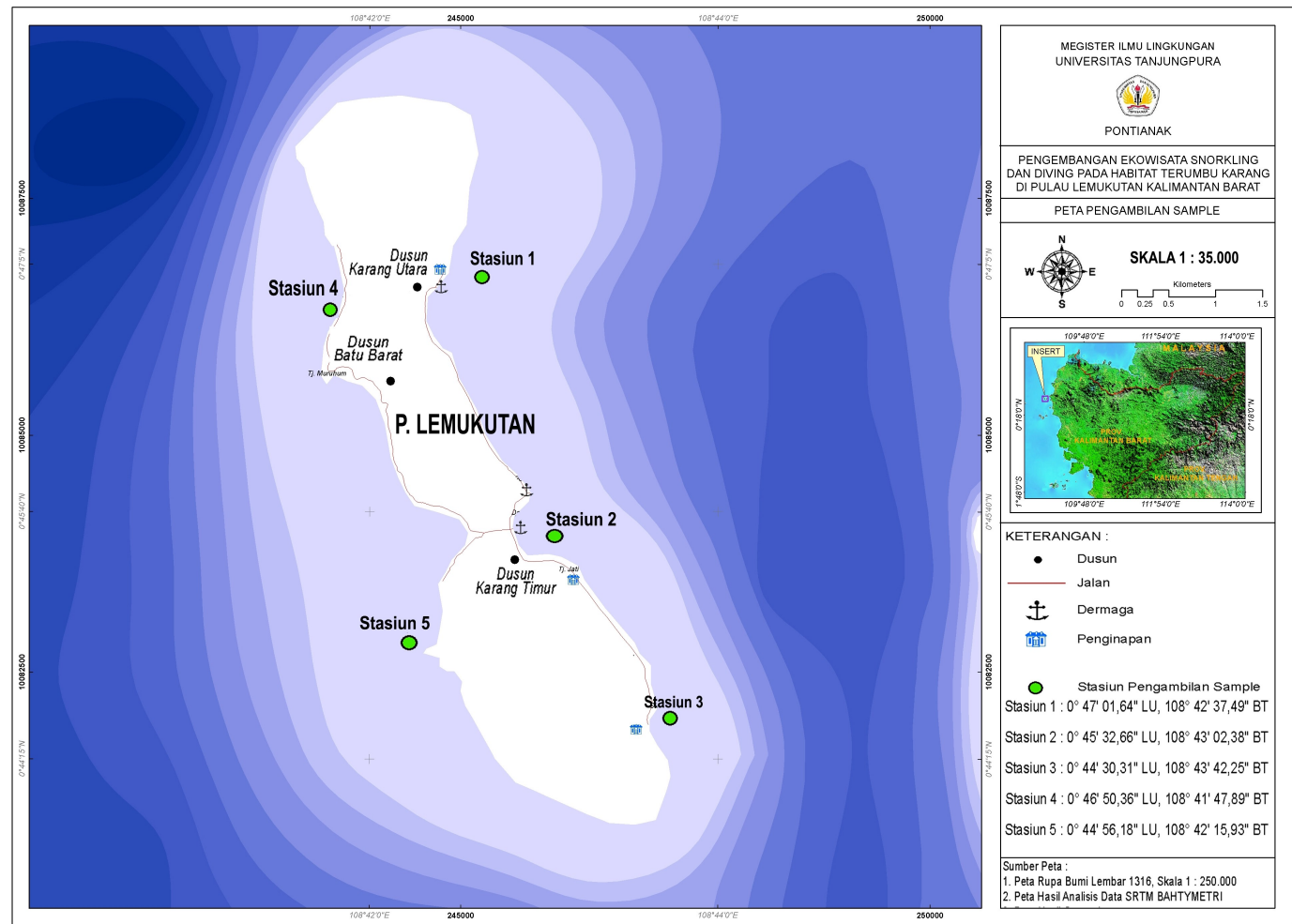

Gambar 1 Lokasi Penelitian

dan jenis life form menggunakan metode LIT (line intercept tansect) pada titik-titik sampling (English et al., 1997). Kondisi terumbu karang disajikan dalam bentuk struktur komunitas yang terdiri dari data: persentase tutupan karang hidup, persentase tutupan karang mati, jumlah koloni, ukuran koloni, frekuensi kehadiran, bentuk pertumbuhan (Suharsono, 1996).

Sedangkan metode yang digunakan untuk pendataan jumlah jenis ikan karang adalah metode Underwater Visual Census (UVC) (English et al., 1997). Pemantauan dilakukan di garis transek yang sama dengan kegiatan penelitian karang, agar sekaligus mendapatkan data bentik yang menggambarkan habitatnya

Data primer yang telah diperoleh kemudian dilakukan pengolahan data dengan cara menghitung Persentase Pe- nutupan (Percent cover) (Commission et al., 1993), yaitu :

$n_{i}=\frac{l_{i}}{L} \times 100 \%$

dimana; ni : persentase penutupan karang hidup; li: panjang karang; L : panjang transek garis

Menurut Commission et al. (1993), Sukmara et al. (2001) nilai persentase penutupan, sebagai penduga kondisi terumbu karang dapat dikategorikan Sangat Jelek (0 - 10\%); Jelek (11 - 30\%); Sedang (31 - 50\%); Baik (51 - 75\%); Sangat Baik (76 - 100\%). Sementara analisis banyaknya Jenis ikan menggunakan buku identifikasi ikan (Allen et al., 2003), data yang telah dicatat di masukkan ke dalam tabel dan dihitung jumlah jenis ikan yang di temukan dalam tiap stasiun. 
Analisis Kesesuaian ekowisata snorkling dan diving mengacu pada Yulianda (2007). Berdasarkan matrik analisis kesesuaian ekowisata snorkling. Pada matriks analisis kesesuaian ekowisata snorkling terdapat beberapa kriteria yang harus diukur yaitu kecerahan, tutupan karang, jenis life form, jenis ikan karang, kecepatan arus, kedalaman, dan luas hamparan datar karang.

Perhitungan Indeks Kesesuaian Wisata bahari berdasarkan Yulianda (2007) Rumus yang digunakan untuk menghitung indeks kesesuaian wisata adalah:

$I K W=\left(\frac{\sum n_{i}}{N_{\max }}\right) \times 100 \%$

dimana; IKW : indeks kesesuaian wisata; $\mathrm{Ni}$ : nilai parameter ke-i (bobot $\mathrm{x}$ skor); $\mathrm{N}$ maks : nilai maksimum dari suatu kategori wisata (snorkeling $=57$, Diving = 54).

Klasifikasi Sangat Sesuai (S1) jika nilai IKW 83-100\%, dikatakan Cukup Sesuai (S2) jika nilai IKW $50-<83 \%$, Sesuai Bersyarat (S3) jika nilai IKW $17-<50 \%$ dan Tidak Sesuai (N) jika nilai IKW $<17 \%$.

Metode perhitungan dilakukan dengan menggunakan konsep daya dukung kawasan /DDK (Yulianda, 2007):

$D D K=K x \frac{l_{p}}{l_{t}} x \frac{W_{t}}{W_{p}}$

dimana; DDK : Daya Dukung Kawasan; K : Potensi ekologis pengunjung per satuan unit area (orang); Lp : Luas Area $\left(\mathrm{m}^{2}\right)$ atau panjang area $(\mathrm{m})$ yang dapat dimanfaatkan; Lt : Unit area untuk kategori tertentu $\left(\mathrm{m}^{2}\right)$; Wt : Waktu yang disediakan kawasan untuk wisata dalam 1 hari (jam); Wp : Waktu yang dihabiskan oleh pengunjung untuk setiap kegiatan tertentu (jam).

Perhitungan DDK terdapat angka yang sudah ditentukan dalam tiap kategori wisata, untuk snorkeling $\mathrm{K}=1, \mathrm{Wp}=$ 3 , Wt $=6$, dan $\mathrm{Lt}=500 \mathrm{~m}^{2}$. Sedangkan untuk diving $\mathrm{K}=2, \mathrm{Wp}=2, \mathrm{Wt}=$ 8 , dan $\mathrm{Lt}=2000 \mathrm{~m}^{2}$. Lp dihitung luas area atau panjang area yang dapat dimanfaatkan untuk ekowisata snorkling pada suatu kawasan. Eksplorasi wisata dalam konservasi diatur oleh ketentuan PP No.18/1994 tentang Pengusahaan Pariwisata Alam di Zona Pemanfaatan Taman Nasional dan taman wisata alam, maka areal yang diizinkan untuk dikembangkan adalah $10 \%$ dari luas zona pemanfaatan. Sehingga DDK dalam kawasan konservasi perlu dibatasi dengan Daya Dukung Pemanfaatan (DDP) dengan rumus (Yulianda, 2007)

$D D P=0,1 x D D K$

Perumusan strategi pengelolaan terumbu karang P. Lemukutan sangat dibutuhkan dalam menentukan perencanaan pengembangan kawasan tersebut secara berkelanjutan. Penentuan strategi dilakukan dengan menggunakan metode analisis SWOT. Berbagai data yang akan dianalisis seperti kondisi terumbu karang, sarana prasarana, dukungan masyarakat, aksesibilitas, SDM, kelembagaan, pemasaran, promosi, kebijakan pemerintah, letak geografis, kecenderungan ekowisata, persaingan wisata, kerusakan terumbu karang dan cuaca. Hasil analisis ini akan ditampilkan dalam bentuk uraian deskriptif, tabulasi dan gambar.

Selanjutnya data dan informasi tersebut disusun kedalam sebuah matrik faktor strategi internal (IFAS) dan ekster- 
Tabel 1 . Matriks Kesesuaian Lokasi Untuk Wisata Snorkeling

\begin{tabular}{|c|c|c|c|c|c|c|c|c|c|c|}
\hline \multirow{2}{*}{ No } & \multirow{2}{*}{ Parameter Perairan } & Bobot & Kategori & \multirow{2}{*}{ Skor } & Kategori & \multirow{2}{*}{ Skor } & Kategori & \multirow{2}{*}{ Skor } & Kategori & \multirow{2}{*}{ Skor } \\
\hline & & (B) & S1 & & S2 & & S3 & & $\mathrm{N}$ & \\
\hline 1 & Kecerahan Perairan $(\%)$ & 5 & 100 & 3 & $80-<100$ & 2 & $20-<80$ & 1 & $<20$ & 0 \\
\hline 2 & Tutupan Karang (\%) & 5 & $>75$ & 3 & $>50-75$ & 2 & $25-50$ & 1 & $<25$ & 0 \\
\hline 3 & Jenis Life form & 3 & $>12$ & 3 & $>7-12$ & 2 & $4-7$ & 1 & $<4$ & 0 \\
\hline 4 & Jenis Ikan Karang & 3 & $>50$ & 3 & $30-50$ & 2 & $10-<30$ & 1 & $<10$ & 0 \\
\hline 5 & Kecepatan Arus $(\mathrm{cm} / \mathrm{det})$ & 1 & $0-15$ & 3 & $>15-30$ & 2 & $>30$ & 1 & $>50$ & 0 \\
\hline 6 & Kedalaman Karang (m) & 1 & $1-3$ & 3 & $>3-6$ & 2 & $>6-10$ & 1 & $>10$ & 0 \\
\hline
\end{tabular}

Tabel 2 Matriks Kesesuaian Lokasi Untuk Wisata Diving

\begin{tabular}{|c|c|c|c|c|c|c|c|c|c|c|}
\hline \multirow{2}{*}{ No } & \multirow{2}{*}{ Parameter Perairan } & \multirow{2}{*}{$\begin{array}{c}\text { Bobot } \\
\text { (B) }\end{array}$} & \multirow{2}{*}{$\begin{array}{c}\text { Kategori } \\
\text { S1 }\end{array}$} & \multirow{2}{*}{ Skor } & \multirow{2}{*}{$\begin{array}{c}\text { Kategori } \\
\text { S2 }\end{array}$} & \multirow{2}{*}{ Skor } & Kategori & \multirow{2}{*}{ Skor } & Kategori & \multirow{2}{*}{ Sko } \\
\hline & & & & & & & S3 & & $\mathrm{N}$ & \\
\hline 1 & Kecerahan Perairan $(\%)$ & 5 & $>80$ & 3 & $50-<80$ & 2 & $20-<50$ & 1 & $<20$ & 0 \\
\hline 2 & Tutupan Karang (\%) & 5 & $>75$ & 3 & $>50-75$ & 2 & $25-50$ & 1 & $<25$ & 0 \\
\hline 3 & Jenis Life form & 3 & $>12$ & 3 & $>7-12$ & 2 & $4-7$ & 1 & $<4$ & 0 \\
\hline 4 & Jenis Ikan Karang & 3 & $>100$ & 3 & $50-100$ & 2 & $20-<50$ & 1 & $<20$ & 0 \\
\hline 5 & Kecepatan Arus $(\mathrm{cm} / \mathrm{det})$ & 1 & $0-15$ & 3 & $>15-30$ & 2 & $>30-50$ & 1 & $>50$ & 0 \\
\hline 6 & Kedalaman Karang (m) & 1 & $6-15$ & 3 & $>15-20$ & 2 & $>20-30$ & 1 & $>30$ & 0 \\
\hline
\end{tabular}

nal (EFAS). Selanjutnya dibuat kemungkinan strategi pengembangan berdasarkan pertimbangan kombinasi empat set faktor strategis tersebut. Faktor-faktor EFAS dan IFAS di transfer ke dalam matrik diagram silang SWOT. Berdasarkan pendekatan tersebut, dapat dibuat berbagai kemungkinan alternatif strategi (SO, ST, WO, WT) (Rangkuti, 1998).

\section{HASIL DAN PEMBAHASAN}

Wilayah pulau Lemukutan memiliki luas wilayah kurang lebih $11,1 \mathrm{~km}^{2}$ atau sekitar 1.112 hektar. Pulau ini memiliki pantai-pantai yang landai dengan hamparan pasir dan dilengkapi dengan batu-batuan. Pulau ini memiliki aksesibilitas yang mudah untuk dikunjungi, jalur darat dari Bandara Supadio Pontianak selama \pm 3 jam, dari ibukota Kabupaten Bengkayang \pm 1 jam sedangkan dari kota singkawang \pm 15 menit menuju dermaga teluk suak, dilanjutkan jalur laut ditempuh $\pm 1,5$ jam menggunakan kapal penumpang yang ratarata bermuatan 30 orang.
Kondisi jalan di pulau ini masih belum tertata dengan baik, banyak jalan rabat beton yang sudah rusak, lebar jalan 12 m untuk menghubungkan dusun satu dengan dusun lainnya. Listrik PLN beroperasi waktu malam pada pukul 17.00 wib 05.00 wib sedangkan pada beberapa penginapan menggunakan genset untuk beroperasi di siang hari. Air bersih diambil dari sumber mata air yang ada di bukit. Pengelolaan air di daerah ini sudah lebih modern menggunakan alat ukur air (meteran) yang dikelola oleh desa setempat.

Masyarakat di Pulau Lemukutan mayoritas memiliki latar belakang pekerjaan sebagai nelayan serta petani karena pulau ini memiliki sumberdaya alam yang potensial seperti lahan untuk perkebunan cengkeh dan pala serta hasil laut yang sampai sekarang menjadi andalan dalam memenuhi kebutuhan rumah tangga, hasil perikanan daerah ini menggunakan alat tangkap seperti jaring, bubu dan pancing, bagan tancap.

Salah satu aspek yang diperlukan dalam pengembangan ekowisata adalah ada tidaknya kehendak masyarakat un- 
tuk mengembangkan pariwisata setempat, sehingga peran serta masyarakat harus mendapat pertimbangan dalam segala hal. Berdasarkan hasil wawancara, sebanyak $90 \%$ masyarakat memahami tentang pengertian wisata bahari, dan setuju jika Pulau Lemukutan dikembangkan untuk kegiatan wisata bahari dan selanjutnya menganggap perairan sekitar pulau lemukutan agar cocok untuk aktivitas Snorkeling dan diving.

Secara umum masyarakat desa P. Lemukutan setuju jika di libatkan dalam kegiatan pengembangan wisata snorkeling dan diving dengan persentase sebanyak 96,7\%. Menurut mereka wisata snorkling dan diving tidak mengganggu aktifitas mereka dalam mencari nafkah utama dan justru akan meningkatkan penghasilan.

Parameter Kualitas perairan yang terkait dengan wisata Snorkling dan diving adalah Kecerahan, Arus, Bathimetri, dan Lebar Hambaran Karang. Kecerahan di Lokasi penilaian 100\%, Kecepatan Arus berkisar antara $0,10 \mathrm{~m} / \mathrm{s}$ sampai $0,25 \mathrm{~m} / \mathrm{s}$, Semua stasiun penelitian mempunyai rata-rata kedalaman yang sesuai untuk pengembangan ekowisata snorkling yaitu $<3 \mathrm{~m}$ dan $d i$ ving di kedalaman 6 meter, sedangkan dari hasil pengolahan data luas total terumbu karang di Pulau Lemukutan \pm 2.719 Ha dengan rincian Stasiun 1 (763 Ha), Stasiun 2 (482 Ha), Stasiun 3 (464 Ha) Stasiun 4 (483 Ha) dan Stasiun 5 (527 Ha).

Berdasarkan hasil analisis penilaian melalui scorring diperoleh hasil kesesuaian wisata Snorkling dan diving disajikan pada Tabel 3 dan Tabel 4 berikut ini.
Hasil analisis data kesesuaian untuk wisata snorkeling pada tabel diatas menunjukkan bahwa 4 stasiun yaitu stasiun 1,2 , 3, dan 5 masuk dalam kategori Cukup Sesuai (S2) dengan nilai masing-masing 75,4\%, 64,9\%, 73,6\% dan $80,7 \%$. Sedangkan stasiun 4 masuk dalam kategori Sangat Sesuai (S1) dengan nilai $89,4 \%$.

Hasil analisis data kesesuaian untuk wisata diving pada tabel diatas menunjukkan bahwa ke 5 stasiun sampling wisata diving yaitu stasiun 1, 2, 3, 4 dan 5 masuk dalam kategori Cukup Sesuai (S2) dengan nilai masing-masing 70,4\%, $55,5 \%, 68,5 \%, 79,6 \%$ dan70,3\%

Salah satu parameter penting yang harus diperhatikan oleh wisatawan dalam melakukan aktivitas Snorkeling adalah kedalaman. Dalam Matriks kesesuaian wisata Snorkling (Yulianda, 2007) kedalaman yang paling sesuai adalah 1 $3 \mathrm{~m}$, hal ini selain lebih dekat dan lebih jelas dengan objek yang akan dilihat juga pada umumnya para pengunjung Snorkling lebih memilih pada kedalaman yang relatif aman, nyaman dan mengutamakan keselamatan dalam melakukan aktivitas tersebut. Sedangkan kedalaman untuk aktivitas diving yang paling sesuai adalah $6-15 \mathrm{~m}$, hal ini selain pengaruh tekanan air tidak terlalu besar pada kedalaman tersebut juga akan lebih stabil dalam bergerak dan mengurangi pengaruh gerakan gelombang permukaan. Maka Pemetaan Zona Wisata Snorkling dipilih pada kedalaman 1-3 m dan diving pada 6 - 15 $m$ yang di overlay dengan tutupan karang.

Penghitungan daya dukung kawasan dilakukan terhadap tiap zona wisata yang dianggap sangat sesuai (S1) dan Sesuai (S2) dengan asumsi bahwa wisata- 
Tabel 3 Hasil Analisis Kesesuaian Wisata Snorkling

\begin{tabular}{|c|c|c|c|c|c|c|c|c|c|c|c|c|}
\hline \multirow{2}{*}{ No } & \multirow{2}{*}{ Parameter } & \multirow{2}{*}{ Bobot } & \multirow{2}{*}{$\begin{array}{c}\text { Stasiun } 1 \\
\text { Skor }\end{array}$} & \multirow{2}{*}{ Nilai } & \multirow{2}{*}{$\begin{array}{c}\text { Stasiun } 2 \\
\text { Skor }\end{array}$} & \multirow{2}{*}{ Nilai } & \multirow{2}{*}{$\begin{array}{c}\text { Stasiun } 3 \\
\text { Skor }\end{array}$} & \multirow{2}{*}{ Nilai } & \multirow{2}{*}{$\begin{array}{c}\text { Stasiun } 4 \\
\text { Skor }\end{array}$} & \multirow{2}{*}{ Nilai } & \multirow{2}{*}{$\begin{array}{c}\text { Stasiun } 5 \\
\text { Skor }\end{array}$} & \multirow{2}{*}{ Nila } \\
\hline & & & & & & & & & & & & \\
\hline 1 & Kecerahan Perairan (\%) & 5 & 3 & 15 & 3 & 15 & 3 & 15 & 3 & 15 & 3 & 15 \\
\hline 2 & Tutupan Karang (\%) & 5 & 2 & 10 & 1 & 5 & 2 & 10 & 3 & 15 & 2 & 10 \\
\hline 3 & Jenis Life form & 3 & 2 & 6 & 2 & 6 & 2 & 6 & 2 & 6 & 2 & 6 \\
\hline 4 & Jenis Ikan Karang & 3 & 1 & 3 & 1 & 3 & 1 & 3 & 2 & 6 & 2 & 6 \\
\hline 5 & Kecepatan Arus (cm/dtk) & 1 & 3 & 3 & 2 & 2 & 2 & 2 & 3 & 3 & 3 & 3 \\
\hline 6 & Kedalaman Terumbu Karang (m) & 1 & 3 & 3 & 3 & 3 & 3 & 3 & 3 & 3 & 3 & 3 \\
\hline \multirow[t]{2}{*}{7} & Luas hamparan karang (m) & 1 & 3 & 3 & 3 & 3 & 3 & 3 & 3 & 3 & 3 & 3 \\
\hline & TOTAL & & & 43 & & 37 & & 42 & & 51 & & 46 \\
\hline
\end{tabular}

Tabel 4 Hasil Penilaian Kesesuaian Wisata Diving

\begin{tabular}{|c|c|c|c|c|c|c|c|c|c|c|c|c|}
\hline \multirow{2}{*}{ No } & \multirow{2}{*}{ Parameter } & \multirow{2}{*}{ Bobot } & \multirow{2}{*}{$\begin{array}{c}\text { Stasiun } 1 \\
\text { Skor }\end{array}$} & \multirow{2}{*}{ Nilai } & \multirow{2}{*}{$\begin{array}{c}\text { Stasiun } 2 \\
\text { Skor }\end{array}$} & \multirow{2}{*}{ Nilai } & \multirow{2}{*}{$\begin{array}{c}\text { Stasiun } 3 \\
\text { Skor }\end{array}$} & \multirow{2}{*}{ Nilai } & Stasiun 4 & \multirow{2}{*}{ Nilai } & \multirow{2}{*}{$\begin{array}{c}\text { Stasiun } 5 \\
\text { Skor }\end{array}$} & \multirow{2}{*}{ Nilai } \\
\hline & & & & & & & & & Skor & & & \\
\hline 1 & Kecerahan Perairan $(\%)$ & 5 & 3 & 15 & 3 & 5 & 3 & 15 & 3 & 15 & 3 & 15 \\
\hline 2 & Tutupan Karang (\%) & 5 & 2 & 10 & 1 & 5 & 2 & 10 & 3 & 15 & 2 & 10 \\
\hline 3 & Jenis Life form & 3 & 2 & 6 & 2 & 6 & 2 & 6 & 2 & 6 & 2 & 6 \\
\hline 4 & Jenis Ikan Karang & 3 & 1 & 3 & 0 & 0 & 1 & 3 & 1 & 3 & 2 & 3 \\
\hline 5 & Kec. Arus (cm/dtk) & 1 & 2 & 2 & 2 & 2 & 1 & 1 & 2 & 2 & 3 & 2 \\
\hline \multirow[t]{3}{*}{6} & Kedalaman Karang (m) & 1 & 2 & 2 & 2 & 2 & 2 & 2 & 2 & 2 & 2 & 2 \\
\hline & TOTAL & & & 39 & & 31 & & 38 & & 44 & & 39 \\
\hline & IKW (N Max 54) & & & 70,4 & & 55,5 & & 68,5 & & 79,6 & & 70,3 \\
\hline
\end{tabular}

Tabel 5 Nilai Daya Dukung Kawasan Ekowisata Bahari di Pulau Lemukutan

\begin{tabular}{lcccc}
\hline \multirow{2}{*}{ No. } & \multirow{2}{*}{ Jenis Wisata } & Luas Area yang Dimanfaatkan/ Potensi Ekologis (Lp) & Nilai DDK & Nilai DDP \\
\cline { 3 - 5 } & & & (Orang/Hari) & $($ Orang/Hari) \\
\hline 1 & Snorkeling & $15.347 .572 \mathrm{~m}^{2}$ & 61.39 & 6.139 \\
2 & Diving & $5.043 .248 \mathrm{~m}^{2}$ & 10.086 & 71.476 \\
\hline & Total & $20.390 .820 \mathrm{~m}^{2}$ & 7.147 \\
\hline
\end{tabular}

wan yang datang terspesifikasi berdasarkan jenis kegiatan wisatanya. Luas area yang dapat dimanfaatkan/potensi ekologis untuk kegiatan snorkling dan diving dihasilkan dari digitasi peta hasil analisis kesesuaian wisata. Untuk lebih jelasnya dapat dilihat pada Tabel 5 dan Gambar 2.

Daya dukung ekologi untuk kegiatan wisata snorkeling dan diving di Pulau Lemukutan yakni 71.476 orang per hari. Sedangkan pengembangan kawasan yang di izinkan menurut Yulianda (2007)adalah 10\% dari Luas Zona Pemanfaatan, sehingga Daya Dukung Kawasan perlu dibatasi dengan Daya Dukung Pemanfaatan. Daya dukung wisata Diving memiliki jumlah yang lebih kecil dibanding wisata Snorkeling, oleh karena keterbatasan kawasan terumbu karang dan kedalaman yang sesuai. Namun demikian daya dukung wisata diving masih memungkinkan untuk ditambah. Davis and Tisdell (1995) (1995) menyatakan daya dukung kegiatan wisata selam masih dapat ditingkatkan, tergantung dari pengetahuan penyelam dalam berinteraksi dengan terumbu karang.

Analisis ini digunakan untuk memperoleh hubungan antara faktor internal dan eksternal. Faktor internal adalah kekuatan (strength) dan kelemahan (weakness) sedangkan faktor eksternal adalah peluang (opportunity) dan ancaman (threat). Keterkaitan antar faktor tersebut digambarkan dalam matriks SWOT yang akan digunakan untuk menentuk- 


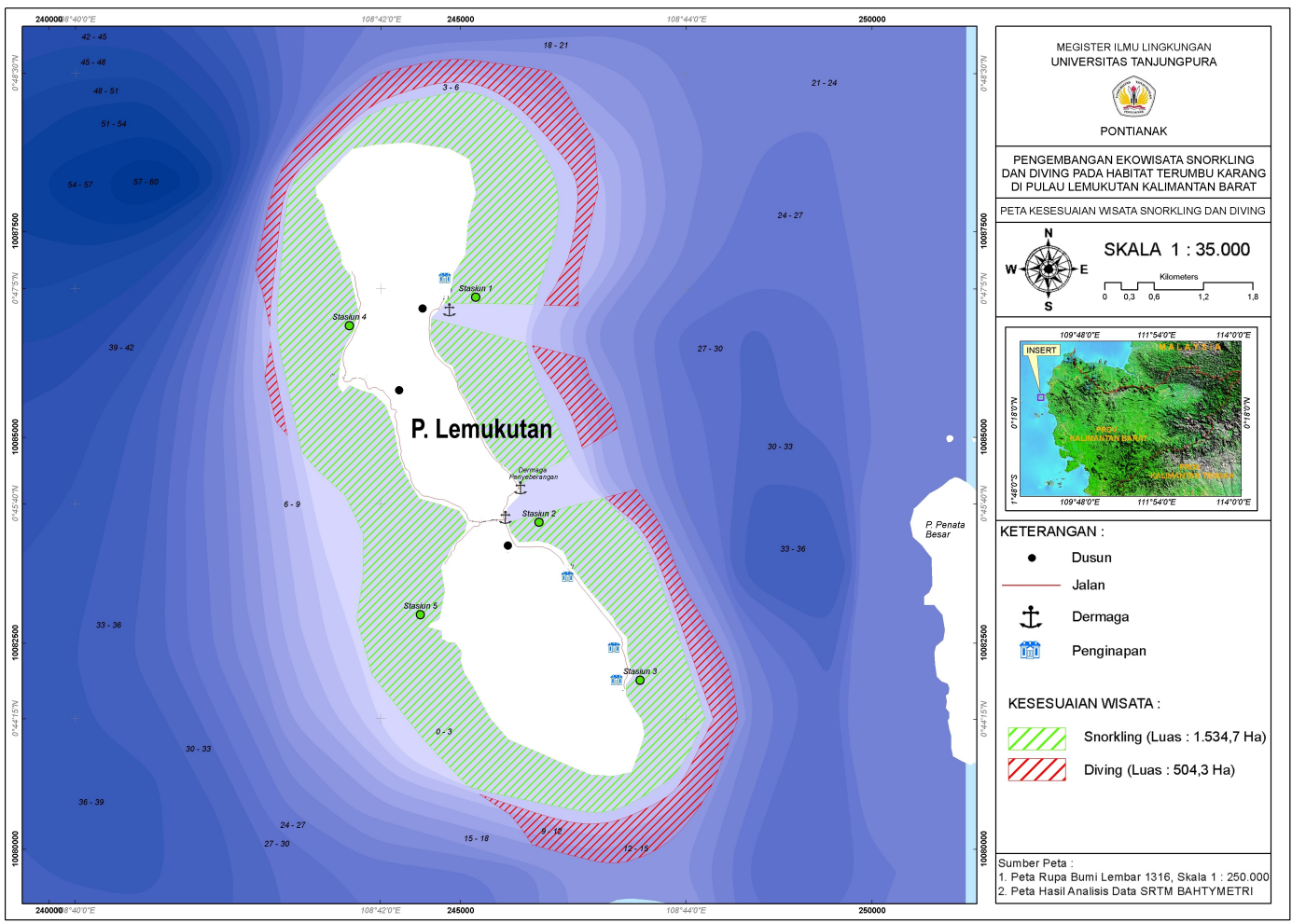

Gambar 2 Digitasi peta hasil analisis kesesuaian wisata

Tabel 6 Matriks Internal Factor Analysis Summary (IFAS)

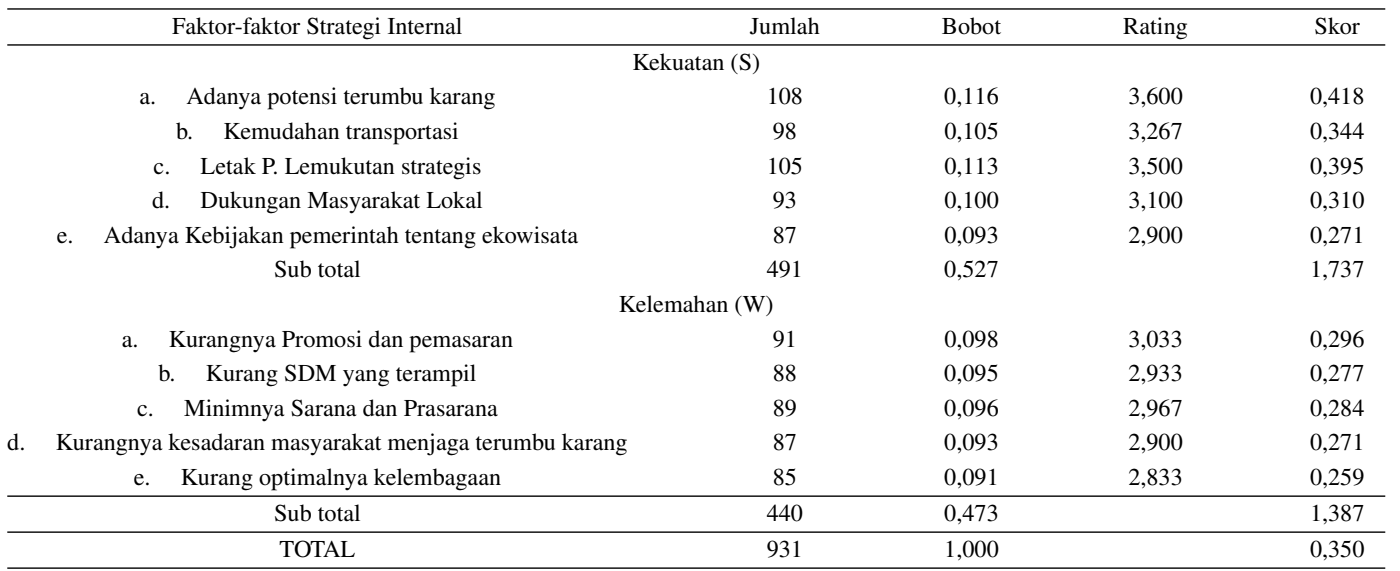

an alternatif strategi pengembangan ekowisata. Pemilihan alternatif strategi dilakukan dengan pemberian nilai pada setiap unsur SWOT dan pemberian rangking yang dilakukan secara subjektif dari hasil wawancara dengan responden. Untuk memilih alternatif strategi ini diberi bobot sebagai berikut : 4 :
Sangat setuju; 3 : Setuju; 2 : Cukup Setuju; 1 : Kurang Setuju.

Hasil identifikasi jenis-jenis masalah dari hasil wawancara dengan beberapa responden, diperoleh lima faktor utama kekuatan dan lima faktor kelemahan dalam pengembangan kegiatan wisata snorkeling dan diving. Untuk mengukur sejauhmana kekuatan dan kelemahan yang 
dimiliki dari kegiatan wisata snorkeling dan diving digunakan model matriks Internal Factors Analysis Summary (IFAS), seperti tersaji pada Tabel 6 .

Hasil perhitungan IFAS menunjukkah bahwa faktor internal yang memiliki kekuatan utama adalah Adanya potensi terumbu karang dengan skor 0,418, dan letak Strategis 0,395, kemudahan transportasi dengan skor 0,344 , dukungan masyarakat 0,310 dan adanya kebijakan pemerintah 0,271. Sedangkan kelemahan adalah; Kurangnya Promosi dan pemasaran 0,296, Minimnya Sarana dan Prasarana 0284, Kurang SDM yang terampil 0,277, Kurangnya kesadaran menjaga karang 0,271, Kurang optimalnya kelembagaan 0,259 . Total skor $\mathrm{S} \mathrm{W}=$ 0,350 (positif) artinya kekuatan masih besar dibandingkan kelemahan. Faktor eksternal ditemukan lima faktor yang berpengaruh positif adalah peluang dan lima faktor berpengaruh negatif adalah ancaman. Untuk penilaian faktor strategi eksternal tersebut digunakan model matriks External Factors Analysis Summary (EFAS), seperti tersaji pada Tabel 7.

Hasil analisis tabel EFAS diatas menunjukkan bahwa faktor eksternal utama yang mempengaruhi pengembangan wisata snorkeling dan diving adalah Tersedianya SDM dengan skor 0,381 disusul kesempatan adanya pekerjaan baru 0,352 , peningkatan pengunjung 0,316 , Era digital dan model wisata minat khusus 0,283 dan dukungan pemerintah 0,270. Sedangkan ancaman utama adalah potensi kerusakan karang 0,337, pencemaran lingkungan 0,323 , ekploitasi darat dan laut 0,283 , masuknya budaya non lokal 0,270, dan persaingan pasar wisata 0,183 . Total Skor $\mathrm{O} T=0,206$ (positif) artinya peluang masih besar di- bandingkan dengan ancamannya, jika semua peluang dapat dioptimal akan dapat mengatasi berbagai ancaman tersebut.

Hasil dari analisis terhadap faktor-faktor strategis di lingkungan internal dan eksternal kawasan Pulau Lemukutan, dapat disusun alternatif strategi pengembangan Ekowisata Snorkling dan Diving menggunakan pendekatan strategi strength-opportunity (SO), weaknessesopportunity (WO), strength-threath (ST), dan weakness-threat (WT). Analisis tersebut berdasarkan justifikasi (Rangkuti, 1998) untuk dapat memaksimalkan aspek kekuatan dan peluang serta meminimalkan aspek kelemahan dan ancaman. Matriks SWOT Pengembangan wisata Snorkling dan diving dapat dilihat pada Gambar 3.

Hasil formulasi strategi ini selanjutnya dilakukan penyusunan sasaran prioritas pengembangan yang dilakukan dengan mengkombinasikan antara komponen yang telah disusun dalam analisis SWOT baik faktor Internal (kekuatan dan kelemahan) maupun faktor eksternal (peluang dan ancaman), terdiri dari 8 alternatif strategi pengembangan yang dapat diterapkan. Nilai urutan yang diperoleh dilakukan dengan merangking untuk mendapatkan skala prioritas.

- Strategi S-O Poin A memiliki jumlah skor 2,317 dan menjadi prioritas 1

- Strategi S-O Poin B memiliki jumlah skor 1,977 dan menjadi prioritas 2

- Strategi S-T Point A memiliki Jumlah skor 1,632 dan menjadi prioritas 4 
Tabel 7 Matriks External Factor Analysis Summary (EFAS)

\begin{tabular}{|c|c|c|c|c|c|}
\hline \multicolumn{2}{|r|}{ Faktor-faktor Strategi External } & Jumlah & Bobot & Rating & Skor \\
\hline \multicolumn{6}{|c|}{ Peluang $(\mathrm{O})$} \\
\hline & a. Dukungan Pemerintah & 85 & 0,095 & 2,833 & 0,270 \\
\hline & b. Peningkatan pengunjung & 92 & 0,103 & 3,067 & 0,316 \\
\hline & c. Tersedianya SDM lokal & 101 & 0,113 & 3,367 & 0,381 \\
\hline & d. Terbukanya alternatif pekerjaan baru & 97 & 0,109 & 3,233 & 0,352 \\
\hline & e. Era Digital dan Model Pariwisata Minat Khusus & 87 & 0,098 & 2,900 & 0,283 \\
\hline & Sub total & 462 & 0,518 & & 1,602 \\
\hline & \multicolumn{5}{|c|}{ Ancaman (T) } \\
\hline & a. Potensi Kerusakan Terumbu Karang & 95 & 0,107 & 3,167 & 0,337 \\
\hline & b. Adanya Persaingan pasar wisata lain & 70 & 0,078 & 2,333 & 0,183 \\
\hline c. & Eksploitasi daratan dan laut tanpa memperhatikan kearifan lokal & 87 & 0,098 & 2,900 & 0,283 \\
\hline & d. Potensi pencemaran lingkungan & 93 & 0,104 & 3,100 & 0,323 \\
\hline & e. Masuknya budaya non lokal terhadap budaya lokal & 85 & 0,095 & 2,833 & 0,270 \\
\hline & Sub Total & 430 & 0,482 & & 1,396 \\
\hline & TOTAL & 892 & 1,000 & & 0,206 \\
\hline
\end{tabular}

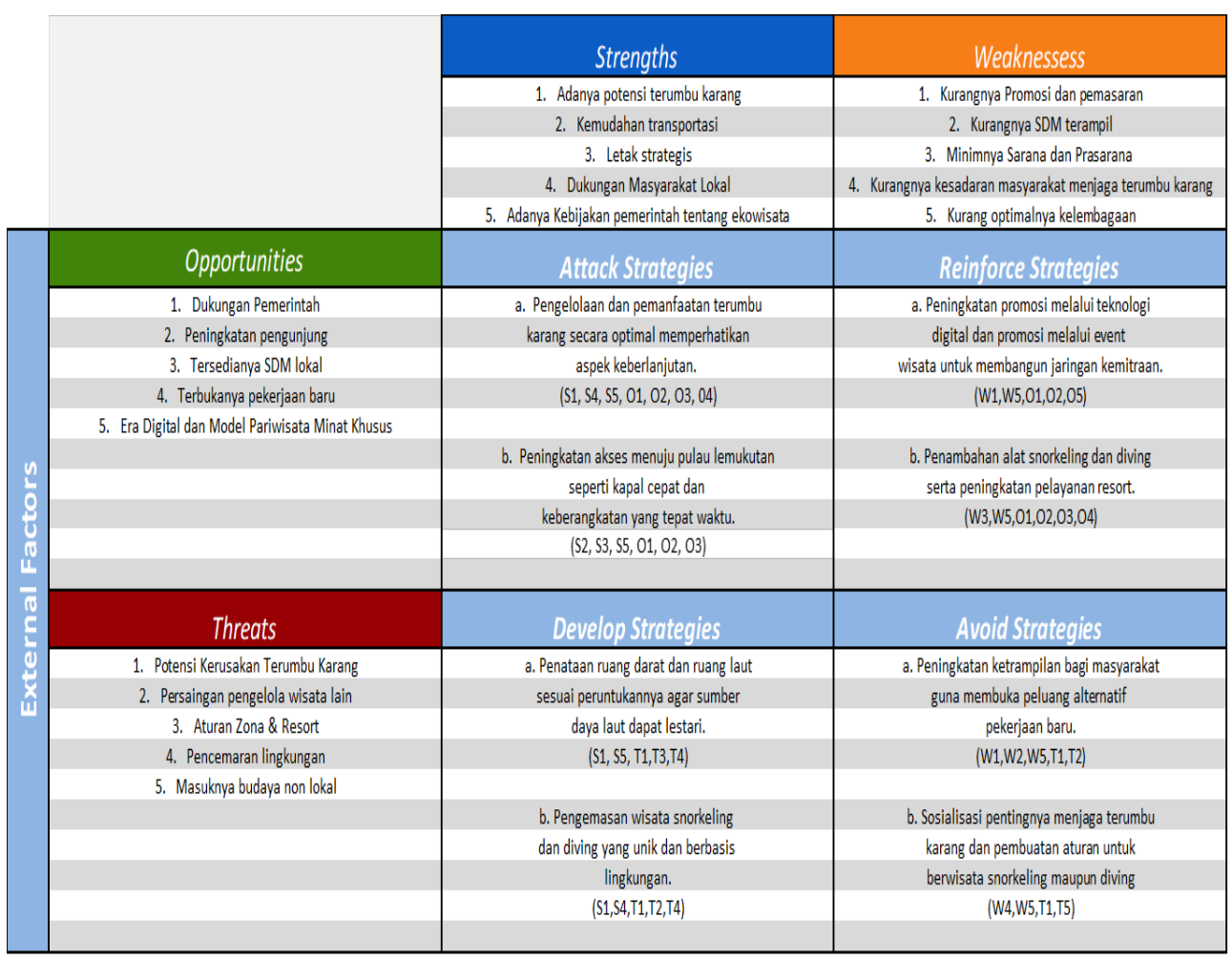

Gambar 3 Matriks SWOT Pengembangan wisata Snorkeling dan diving

- Strategi S-T Point B memiliki Jumlah skor 1,571 dan menjadi prioritas 5

- Strategi W-O Point A memiliki Jumlah skor 1,424 dan menjadi prioritas 6

- Strategi W-O Point B memiliki Jumlah skor 1,861 dan menjadi prioritas 3
- Strategi W-T Point A memiliki Jumlah skor 1,353 dan menjadi prioritas 7

- Strategi W-T Point A memiliki Jumlah skor 1,137 dan menjadi prioritas 8

Selanjutnya, rumusan strategi pengembangan ekowisata Snorkling dan Diving pada Habitat Terumbu Karang di Pulau 
Lemukutan Kabupaten Bengkayang berdasarkan analisis SWOT diatas dapat diuraikan secara lebih rinci sebagai berikut :

1. Pengelolaan dan pemanfaatan terumbu karang secara optimal dengan memperhatikan aspek keberlanjutan. Keberadaan ekosistem terumbu karang memiliki arti yang sangat penting bagi masyarakat Pulau Lemukutan, selain menghasilkan ikan, keberadaan terumbu karang juga merupakan daya tarik wisatawan untuk datang. Pembuatan spot wisata snorkling dan diving yang unik, edukatif dan sesuai dengan kriteria masing masing, dengan tetap memperhatikan aspek daya dukung dan daya tampung kawasan tersebut diperlukan untuk memfasilitasi permintaan wisatawan. Apabila pemanfaatannya tanpa kontrol akan menyebabkan degradasi pada ekosistem tersebut.

2. Peningkatan akses menuju pulau lemukutan, seperti kapal cepat dan keberangkatan yang tepat waktu. Aksesibilitas menjadi salah satu parameter dalam pengembangan wisata. Kemudahan akses menuju kawasan wisata menjadi pertimbangan penting bagi wisatawan yang akan berkunjung. Terkadang untuk menuju ke Pulau Lemukutan para wisatawan bingung harus menyebrang melalui Dermaga Teluk Suak, Pantai Samudra Indah ataupun Sungai Duri. peningkatan akses dapat dilakukan misalnya perbaikan prasarana jalan, dermaga dan menyediakan sarana transportasi yang cepat, tidak terpengaruh pasang surut air laut, yang memenuh standar keselamatan dan terjadwal jam keberangkatannya.
3. Penambahan alat snorkeling dan diving, serta peningkatan pelayanan resort. Penambahan peralatan snorkling dan diving menjadi modal dalam pengembangan wisata ini guna memudahkan wisatawan untuk melakukan aktivitas tersebut, penyewaan alat snorkling dan diving dengan harga terjangkau juga perlu dikaji sesuai dengan daya beli masyarakat, peningkatan prasarana lain seperti penginapan yang bersih dan rapi, juga memberikan kenyamanan dan kepuasan bagi wisatawan, penambahan armada kapal angkutan yang memenuh standar keselamatan. Selain itu sarana transportasi kapal yang terintegrasi dan aman.

4. Penataan ruang darat dan ruang laut sesuai peruntukannya agar sumber daya laut dapat lestari. Kegiatan wisata snorkling dan diving harus dapat selaras dengan Rancangan RZWP3K yang dibuat pemerintah dalam penataan ruang laut pesisir. pembagian zona menjadi sangat penting agar tidak terjadi tumpang tindih kepentingan, sehingga jelas peruntukannya, yang dipakai untuk pariwisata, kelautan dan perikanan, ESDM, Kehutanan, dan lain sebagainya. Penataan ruang wisata yang teratur, rapi dan sehat akan meningkatkan nilai estetika kawasan tersebut, Hal ini juga agar dapat meminimalisir dampak negatif yang ditimbulkan dari kegiatan wisata.

5. Pengemasan wisata snorkling dan $d i$ ving yang unik dan berbasis lingkungan. Perlu adanya pengemasan wisata snorkling dan diving yang menarik, unik dan edukatif berbasis lingkungan agar wisatawan merasakan sesuatu yang beda yang tidak dite- 
mukan di daerah lain, banyak hal yang bisa dilakukan misalnya pembuatan spot taman bawah laut, taman kima, ladang anemon, wreck kapal, apartemen ikan, reef ball, dan juga transplantasi karang, agar menciptakan image berwisata sambil berbuat untuk alam. Selain itu juga dapat dikemas dengan belajar sambil berwisata melalui study tour anak sekolah dengan memberikan pengetahuan tentang ekosistem laut yang bekerjasama dengan instansi tekait dan masyarakat.

6. Peningkatan promosi melalui teknologi digital dan promosi melalui event wisata untuk membangun jaringan kemitraan. Promosi memiliki peranan yang sangat penting dalam upaya pengembangan wisata snorkling dan diving. Promosi yang dilakukan tidak hanya oleh pemerintah dalam agenda pariwisata daerah ataupun dari pihak pengelola melalui media periklanan seperti pembuatan website, media sosial, leaflet, iklan yang dipasang di tempat strategis ataupun even-even yang berkaitan dengan wisata. Namun keterlibatan masyarakat dalam upaya promosi sangat penting. Masyarakat dapat dijadikan salah satu sumber informasi penting tentang potensi wisata snorkling dan diving yang ada di Pulau Lemukutan.

7. Peningkatan ketrampilan bagi masyarakat guna membuka peluang alternatif pekerjaan baru. Pembuatan program pelatihan pemandu ekowisata dan sertifikasi diving bagi masyarakat lokal agar dapat meningkatkan kemampuan dan pengetahuan pemandu wisata sehingga aktifitas snorkeling dan diving tidak mengakibatkan rusaknya terumbu karang.
Selain itu pelatihan pembuatan kerajinan tangan dan panganan khas pulau juga menciptakan peluang pekerjaan baru, seperti sotong gepuk atau rempeyek ikan teri, rempeyek bulu babi yang dapat dijadikan oleholeh. Kegiatan tersebut tentu saja berbasis ecoproduct dan ecotourism.

8. Sosialisasi pentingnya menjaga terumbu karang dan pembuatan aturan untuk berwisata snorkling maupun diving. Penyadartahuan terhadap masyarakat dan wisatawan akan pentingnya terumbu karang, pemasangan slogan-slogan cinta laut di area strategis menjadi salah satu strategi dalam mengurangi tingkat kerusakan karang selain itu pembuatan peraturan pemakaian rompi apung untuk aktivitas snorkling, kepemilikan lisensi diving untuk yang ingin menyelam di area terumbu karang, bagi yang tidak berlisensi kegiatan penyelaman dilakukan di area berpasir dan jauh dari karang. Hal ini bertujuan untuk menjaga keamanan dan keselamatan wisatawan, sekaligus untuk melindungi karang dari kerusakan.

\section{SIMPULAN}

Kondisi perairan P. Lemukutan masuk kategori Cukup Sesuai (S2) untuk dikembangkan sebagai kawasan wisata snorkeling dan diving dengan masing-masing nilai IKW rata-rata $76,8 \%$ dan $68,86 \%$. Daya dukung ekologis perairan P. Lemukutan kategori wisata snorkeling \pm 6.139 orang/hari. Sedangkan wisata diving \pm 1.008 orang/hari. Alternatif strategi pengembangan ekowisata snorkeling dan diving di Pulau Lemukutan di- 
lakukan dengan delapan cara secara hierarki.

\section{Pustaka}

Allen, G. R., Steene, R., Humann, P., and Deloach, N. (2003). Reef fish identification tropical Pacific. New World Publications Incorporated.

Commission, I. O. et al. (1993). Monitoring coral reefs for global change-reference methods for marine pollution studies no. 61. Reference Methods for Marine Pollution Studies.

Dahuri, R. (2003). Keanekaragaman hayati laut: aset pembangunan berkelanjutan Indonesia. Gramedia Pustaka Utama.

Davis, D. and Tisdell, C. (1995). Recreational scuba-diving and carrying capacity in marine protected areas. Ocean \& Coastal Management, 26(1):19-40.

English, S., Wilkinson, C., Baker, V., et al. (1997). Survey manual for tropical marine resources. Townsville (Australia) AIMS.

Kuntjara, E. (2006). Penelitian kebudayaan sebuah panduan praktis. Yogyakarta: Graha Ilmu.

Nawawi, H. and Martini, M. (1996). Penelitian terapan. Yogyakarta: Gadjah Mada University Press.

Rangkuti, F. (1998). Analisis SWOT teknik membedah kasus bisnis. Gramedia Pustaka Utama.

Suharsono (1996). Jenis-jenis karang yang umum dijumpai di perairan Indonesia. Lembaga Ilmu Pengetahuan Indonesia, Pusat Penelitian dan Pengembangan Oseanografi.

Sukmara, A., Siahainenia, A. J., and Rotinsulu, C. (2001). Panduan pemantauan terumbu karang berbasis masyarakat dengan metoda manta tow. Proyek Pesisir CRMP Indonesia.

Yulianda, F. (2007). Ekowisata bahari sebagai alternatif pemanfaatan sumberdaya pesisir berbasis konservasi.[makalah]. In $\mathrm{Di}$ sampaikan pada Seminar Sains Departemen Manajemen Sumberdaya Perairan Fakultas Perikanan dan Ilmu Kelautan Institut Pertanian Bogor, pages 119-129.
Kontribusi: Rudianto, A: mendesain penelitian, merancang metode pengambilan sampel, pengambilan data lapang, analisis data, menyiapkan dan editing manuskrip; Dewi, Y, S K: analisis data, daya dukung wisata, persiapan manuskrip; Burhanudin: pengambilan data, lapang, analisis swot, analisis kesesuaian. 
